\title{
Aplikasi Kehadiran Mahasiswa Secara Otomatis Dengan Smartphone
}

\author{
Nur Ahmad ${ }^{a, 1}$, Saiful Bahri b,2*, Dwi Kristiani ${ }^{a, 3}$ \\ a Fakultas Ilmu Komputer, Universitas Boyolali, Jl. Pandanaran No.405, Boyolali dan Kode Pos, Negara \\ ${ }^{\mathrm{b}}$ Fakultas Pertanian, Universitas Slamet Riyadi, Jl. Sumpah Pemuda No. 18 Kadipiro, Surakarta 57136, Indonesia \\ ${ }^{1}$ nur.95ahmad@gmail.com *; ${ }^{2}$ irsaifulbahrimkom@gmail.com; ${ }^{3}$ dwikristiani45@gmail.com \\ * Koresponsendi penulis
}

ARTICLE INFO

Article history

Menerima 25 Oktober 2019

Revisi 25 Januari 2020

Diterima 30 Januari 2020

\section{ABSTRACT}

\section{ABSTRACT}

This study is titled Application of Student Attendance Online with Smartphone. The research objective is to design, implement, and test student attendance applications automatically with a Smartphone at Boyolali University and produce an online attendance application to improve the learning process and reduce student cheating when attending attendance. The research methodology used is the Iconic process. The results achieved are online attendance applications to facilitate lecturers in making attendance reports and making it easier for students to attend

This is an open access article under the CC-BY-SA 4.0 license.

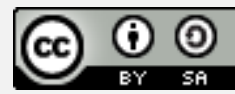

\section{Pendahuluan}

Pendidikan adalah pengembangan potensi diri dalam hal intelektual, spiritual dan emosional. Pendidikan juga berperan membentuk mahasiswa yang berkarakter dan jujur. Mahasiswa adalah seseorang yang sedang dalam proses menimba ilmu ataupun belajar dan terdaftar sedang menjalani pendidikan pada salah satu bentuk perguruan tinggi yang terdiri dari akademik, politeknik, sekolah tinggi, institut dan universitas [1]. Dalam proses belajar mengajar dalam kelas, bukti kehadiran dosen dan mahasiswa dibuktikan dengan adanya lembar presensi atau daftar hadir yang ditandangani oleh mahasiswa dan dosen yang bersangkutan. Absensi adalah suatu pendataan kehadiran, bagian dari pelaporan aktifitas suatu institusi, atau komponen institusi itu sendiri yang berisi data-data kehadiran yang disusun dan diatur sedemikian rupa sehingga mudah untuk dicari dan dipergunakan apabila sewaktu-waktu diperlukan oleh pihak yang berkepentingan.

Berdasarkan hasil observasi di Universitas Boyolali, masih ada masalah ketidakjujuran mahasiswa dalam proses pengisian daftar hadir. Beberapa indikator yang dapat dijadikan dasar untuk mengetahui mahasiswa yang berbohong antara lain perilaku mencontek, fenomena plagiasi dan budaya titip presensi. Absensi merupakan data yang sangat penting dalam setiap kegiatan, baik itu kegiatan perkuliahan maupun kegiatan perkantoran. Namun sering kali data-data absensi ini kurang diperhatikan. Perlu adanya sistem yang dapat menjawab permasalahan diatas yaitu sistem absensi berbasis mobile yang terintegrasi antara proses absensi dan proses rekapitulasi. Sejalan dengan penelitian yang pernah dilakukan oleh [2] berhasil merancang dan membangun aplikasi sistem informasi monitoring absensi mahasiswa Politeknik Negeri Jakarta menggunakan teknologi NFC pada android dengan menggunakan aplikasi web memudahkan administrator untuk melakukan 
kegiatan monitoring evaluasi belajar mengajar dan pengelolaan data absensi kehadiran mahasiswa pada PBM di kelas.

Berdasarkan latarbelakang diatas maka permasalahan dalam penelitian ini dapat dirumuskan yaitu Bagaimana membuat aplikasi kehadiran mahasiswa secara otomatis dengan smartphone di Universitas Boyolali? Sedangkan tujuan penelitiannya adalah untuk merancang, mengimplementasikan dan menguji aplikasi kehadiran mahasiswa secara otomatis dengan smartphone sehingga diharapkan dapat mempermudah Dosen dalam merekap presensi mahasiswa serta mengurangi tindakan mahasiswa yang melakukan kecurangan dengan melakukan titip absen kepada teman yang masuk kuliah.

\section{Tinjauan Pustaka}

Hasil penelitian terdahulu oleh para peneliti lain yang meneliti kasus sejenis dijadikan sebagai bahan referensi. Beberapa penelitian terdahulu adalah sebagai berikut:

Penelitian yang dilakukan oleh [3] dengan judul Sistem Absensi Asisten Dosen Menggunakan Qr Code Scanner Berbasis Android Pada Program Studi Sistem Informasi Universitas Muria Kudus. Tujuan penelitian ini adalah untuk memudahkan para asisten Dosen melakukan absensi dan juga memudahkan laboran ketika melakukan rekapan bulanan. Selain itu Sistem Absensi Asisten Dosen digunakan untuk merekap jumlah kehadiran asisten Dosen dan juga merekap honor yang di dapat setiap asisten Dosen berdasarkan kehadiran asisten Dosen. Metode pengembangan menggunakan Model Waterfall, perancangan menggunakan UML, bahasa pemrograman yang digunakan adalah PHP dan Android dengan Database My SQL. Hasil rancang bangun ini adalah sebuah aplikasi berbasis Android dan web untuk Asisten Dosen Program Studi Sistem Informasi Fakultas Teknik Universitas Muria Kudus.

Penelitian yang dilakukan oleh [2] berhasil merancang dan membangun aplikasi sistem informasi monitoring absensi mahasiswa Politeknik Negeri Jakarta menggunakan teknologi NFC pada android dengan menggunakan aplikasi web. Sistem ini memudahkan administrator untuk melakukan kegiatan monitoring evaluasi belajar mengajar dan pengelolaan data absensi kehadiran mahasiswa pada proses belajar mengajar di kelas.

Penelitian yang dilakukan oleh [4] dengan judul Pengembangan Fungsi Pengajuan Cuti Karyawan pada Sistem Absensi Mobile. Tujuan yang ingin dicapai adalah karyawan dapat mengajukan cuti secara mandiri melalui perangkat mobilenya yang menggunakan minimal sistem operasi Android 4.x untuk dikombinasikan dengan sistem absensi berbasis GPS. Penelitian ini menggunakan metode pengembangan sistem dengan Extreme Programming. Hasil dari sistem absensi yang dikembangkan menunjukkan bahwa telepon pintar berbasis sistem operasi Android dapat digunakan untuk mengajukan cuti karyawan secara mandiri. Keberlanjutan dari sistem ini adalah pengembangan pula fasilitas login sistem yang lebih kredibel contohnya dengan menambahkan fasilitas pemindai data biometrik dari penggunanya.

Penelitian yang dilakukan oleh [5] dengan judul "Sistem Presensi Mahasiswa Dengan Fingerprint Berbasis Website" ini bertujuan untuk menyingkat waktu pada saat proses pengambilan presensi. Selain itu, sistem akan mengurangi tingkat kecurangan mahasiswa terkait kehadiran mahasiswa. Dalam sistem ini, mahasiswa hanya akan diminta untuk mengunggah gambar sidik jarinya untuk menandai kehadiran mahasiswa. Pengembangan sistem ini menggunakan metode waterfall yang melibatkan integrasi dari berbagai teknologi open source berbasis website seperti MySQL, PHP dan Apache Web Server. Hasil dari penelitian ini menunjukkan bahwa sistem ini dapat menyingkat waktu pada saat melakukan proses pengambilan presensi. Selain itu, mahasiswa juga tidak dapat lagi untuk melakukan kecurangan terkait kehadiran mahasiswa.

Penelitian yang pernah dilakukan oleh [6] dengan judul "Perancangan Sistem Absensi Online Menggunakan Android Guna Mempercepat Proses Kehadiran Karyawan Pada PT. Sintech Berkah Abadi", mempunyai tujuan pembaharuan sistem yang baru agar berdampak sangat baik bagi perusahaan dilihat dari sisi efisien, efektif, dan cepat. Sistem absensi online digunakan untuk mempercepat absen melalui smartphone android yang dimiliki oleh masing-masing karyawan. Metode yang digunakan untuk menyelesaikan permasalahan yang terjadi adalah pengumpulan data sistem yang berjalan, wawancara, observasi, analisa sistem yang diusulkan, serta metode prototipe dan testing. 


\section{Metode Penelitian}

Metode yang digunakan untuk pengembangan sistem ini adalah metode ICONIX Process. Pendekatan ICONIX Process didasarkan pada notasi use case. Proses ICONIX, seperti yang diperlihatkan dalam gambar 1, adalah pendekatan minimalis yang disederhanakan yang berfokus pada area yang terletak di antara penggunaan kasus dan kode. Pada penelitian ini peneliti memasukkan setiap langkah - langkah yang terdapat pada model ICONIX Process. Adapun langkah - langkahnya adalah : [7]

a) Pemilihan kasus pada penelitian ini adalah membuat aplikasi kehadiran mahasiswa secara otomatis dengan smartphone di Universitas Boyolali

b) Pengumpulan data, data yang digunakan adalah data presensi mahasiswa.

c) Analisis data, yang digunakan dari ICONIX Proses adalah : pembuatan functional requirement, domain model, use case behavioral requirement, menentukan Technical Architecture dan pembuatan sequence diagram.

d) Perbaikan (Refinement) Requirement review, Robustness Analysis, Preliminary Design Review dan Critical Design Review.

e) Penulisan laporan/dokumentasi merupakan hasil akhir yang berbentuk artikel penelitian

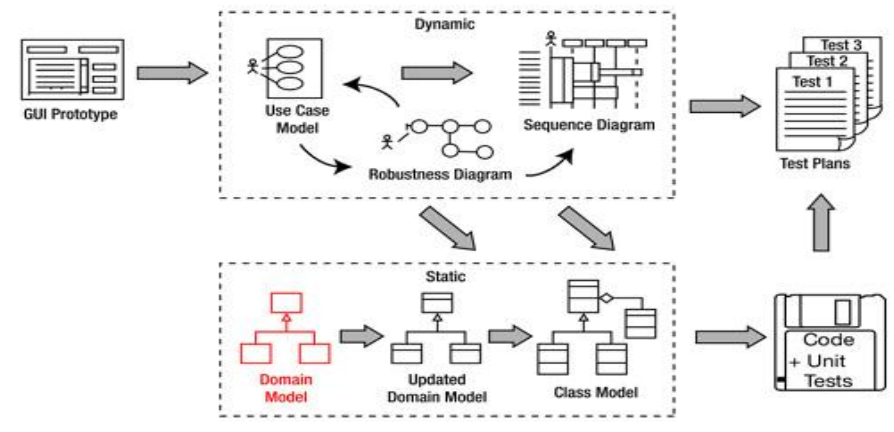

Gambar 1. Metode ICONIX Process

\section{Hasil dan Pembahasan}

Berdasarkan metode yang sudah ditetapkan dan tahapan dalam pengembangan sistem, maka hasilnya adalah sebagai berikut:

Pada langkah pertama menentukan functional requirement atau mendefinisikan kebutuhan fungsional yang diinginkan oleh pengguna. Untuk mendapatkan data-data kebutuhan tersebut maka dilakukan observasi di Universitas Boyolali Jalan Pandanaran no. 405 Boyolali dengan cara mengamati langsung proses presensi yang dilakukan mahasiswa ketika pelaksanaan pembelajaran oleh dosen. Selain itu juga melakukan wawancara dengan mengajukan pertanyaan kepada narasumber mengenai objek penelitian. Hasil obeservasi dan wawancara mendapatkan informasi berupa proses presensi yang masih konvensional dengan menggunakan buku presensi yang dibawa oleh dosen pengajar atau di titipkan di ruang fakultas. Serta berhasil mendapatkan contoh rekap presensi setiap semester oleh dosen.

Diagram Use case mendefinisikan behavioral requirements berdasarkan functional requirement (dan sumber lainnya) yang telah dibuat. Seperti pada Gambar 2 dapat dijelaskan sebagai berikut: Pada aplikasi presensi terdapat 3 aktor yaitu Admin, Mahasiswa dan Dosen. Proses yang dapat dilakukan oleh mahasiswa adalah login untuk dapat masuk ke aplikasi dan melakukan proses absensi. Proses yang dapat dilakukan oleh Dosen adalah login untuk masuk ke aplikasi, menampilkan data jadwal kuliah dan menampilkan hasil sari presensi mahasiswa. Sedangkan untuk admin dapat memberikan akses ke semua menu. Dalam hal ini admin memasukkan data matakuliah yang diambil mahasiswa berdasarkan KRS (Kartu Rencana Studi). 


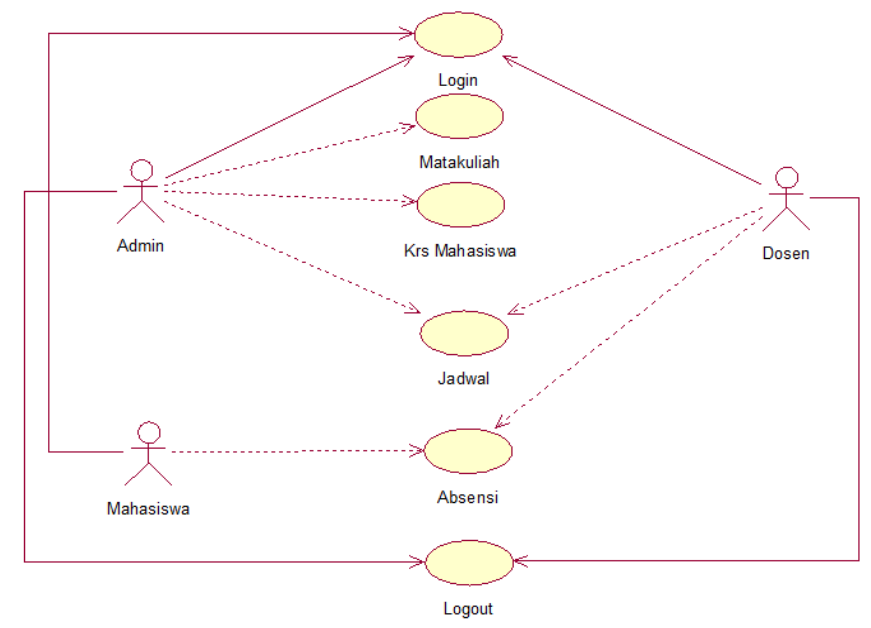

Gambar 2. Use Case Diagram

Diagram aktivitas atau activity diagram menggambarkan aktivitas sistem, bukan apa yang dilakukan oleh aktor. Jadi aktivitas yang dapat dilakukan oleh sistem. Berdasarkan use case diagram dilakukan pembuatan activity diagram agar dapat menjelaskan alur aktivitas aktor terhadap sistem secara detail. Dalam hal ini akan dijelaskan activity diagram untuk mahasiswa dan dosen. Seperti pada Gambar 3 dapat dijelaskan bahwa pertama, mahasiswa melakukan login ke sistem presensi online kemudian memilih menu maka sistem akan menampilkan presensi dari mahasiswa. Mahasiswa harus mengisi kode yang diberikan dosen untuk dapat melakukan absensi. Selanjutnya sistem akan memproses dan menyimpan kedalam database.

Pada Gambar 4 menjelaskan tentang activity diagram Dosen. Dosen melakukan login ke sistem lalu memilih jadwal untuk melihat jadwal matakuliah yang ada pada hari tersebut. Maka selanjutnya Dosen dapat melihat data mahasiswa yang telah melakukan presensi pada hari tersebut. Sedangkan untuk melihat laporan maka dosen dapat memilih menu laporan hasil presensi.

Diagram sequence menggambarkan interaksi antar objek di dalam dan di sekitar sistem (termasuk pengguna, display, dan sebagainya) berupa message yang digambarkan terhadap waktu yang tercantum. Gambaran sequence diagram Admin seperti pada Gambar 5, sequence diagram mahasiswa seperti Gambar 6 dan sequence diagram dosen seperti Gambar 7. Admin dapat mengakses semua menu yang terdapat di dalam aplikasi presensi, antara lain data dosen, data mahasiswa dan data matakuliah. Selain itu Admin juga dapat menambah, mengedit dan menghapus data-data dari mahasiswa maupun dosen.

Penjelasan untuk diagram sequence mahasiswa yang ditunjukkan pada Gambar 6 yaitu mahasiswa dapat mengakses halaman awal dari sistem selanjutnya memilih menu, data absensi, memilih matakuliah, mengisi tanggal absensi dan kode yang diberikan oleh dosen. Data absensi yang dimasukkan secara otomatis akan dikirim ke dosen. Penjelasan untuk Gambar 7 yaitu diagram sequence Dosen adalah Dosen mengakses aplikasi lalu akan ditampilkan halaman awal. Dosen memilih jadwal untuk melihat jadwal matakuliah yang diampu kemudian memilih data absensi untuk melihat mahasiswa yang sudah melakukan presensi pada matakuliah yang diikuti. Selanjutnya untuk dapat melihat rekapan presensi, Dosen memilih menu laporan. 


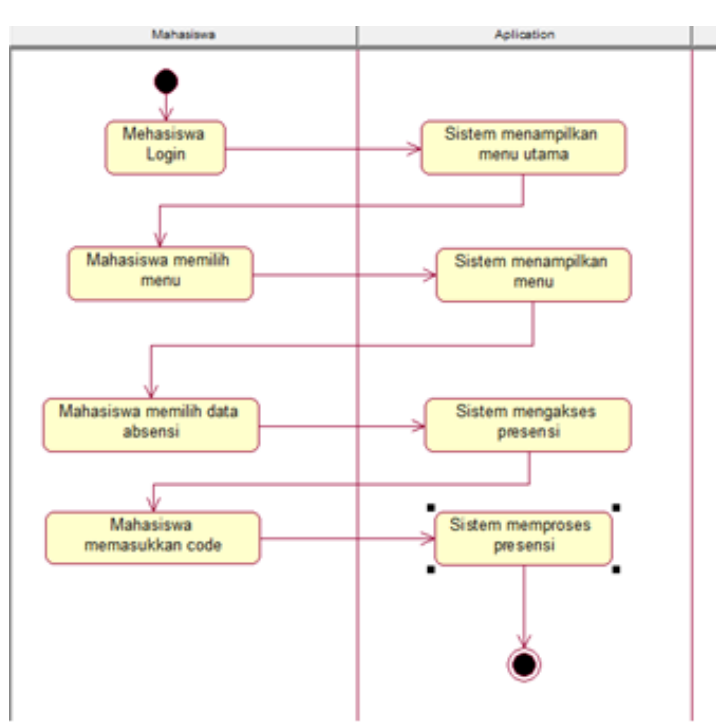

Gambar 3. Activity Diagram Mahasiswa

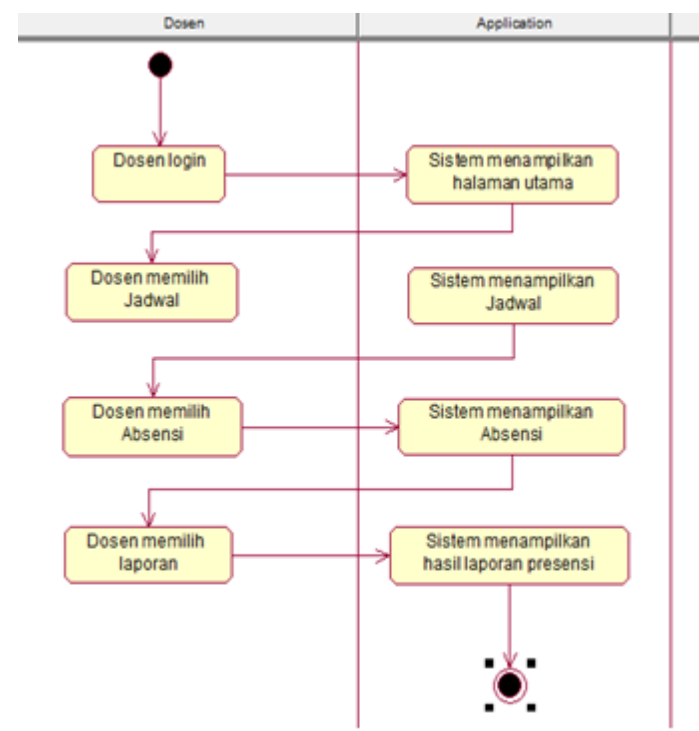

Gambar 4. Activity Diagram Dosen

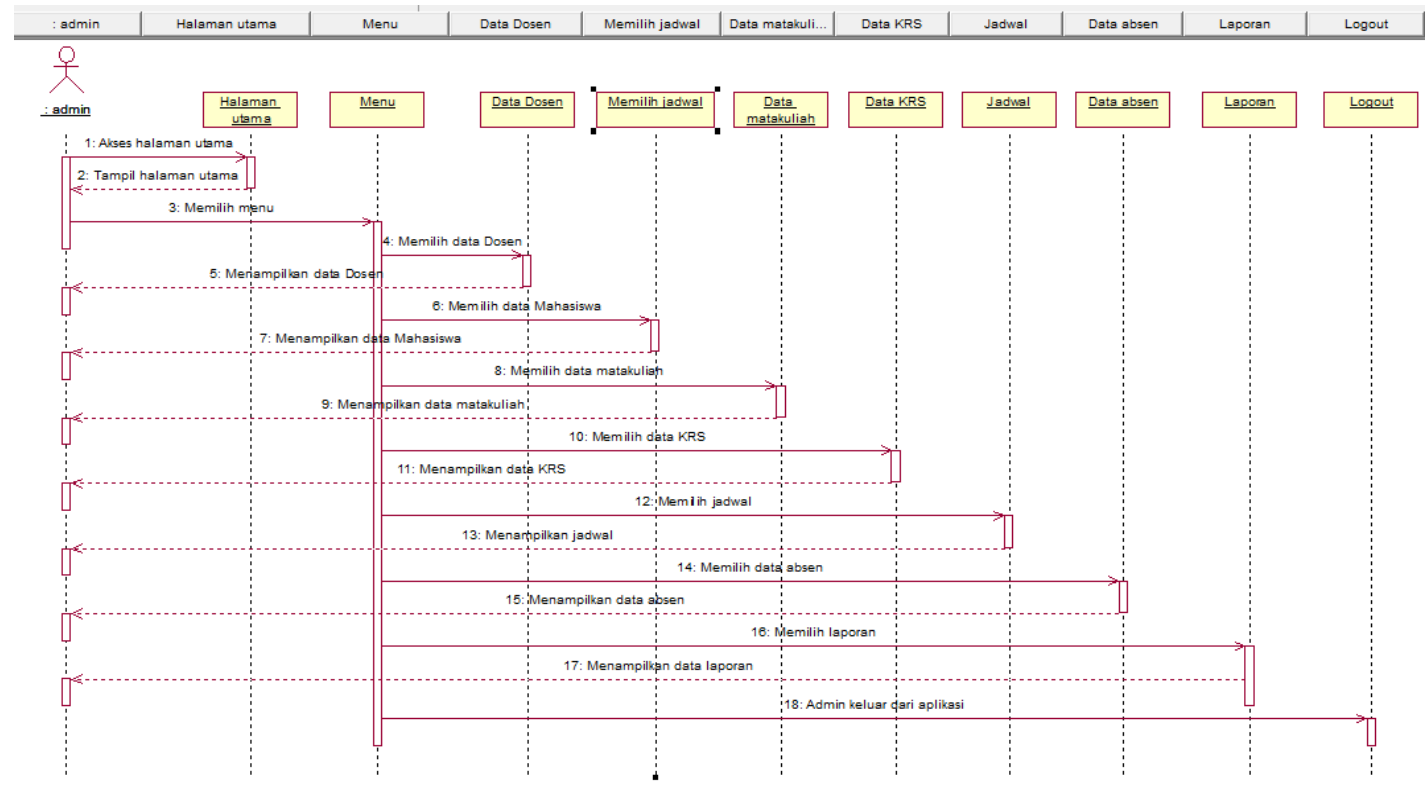

4

Gambar 5. Sequence Diagram Admin 


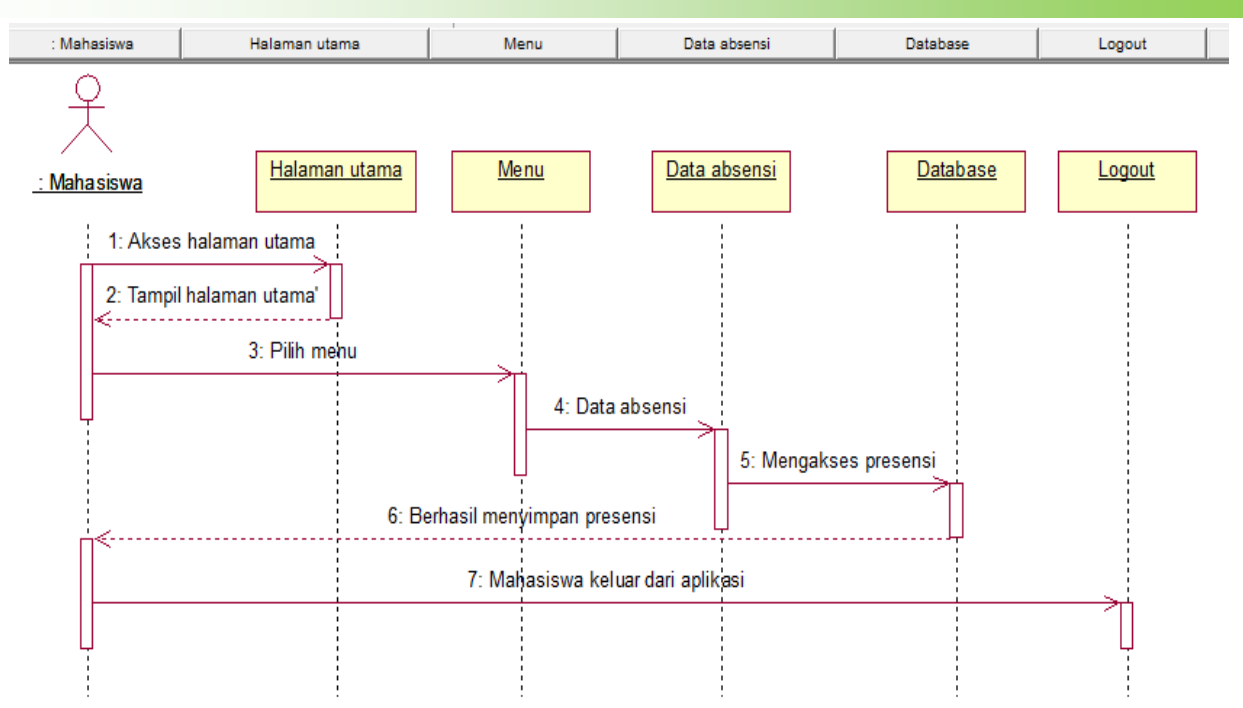

Gambar 6. Mahasiswa

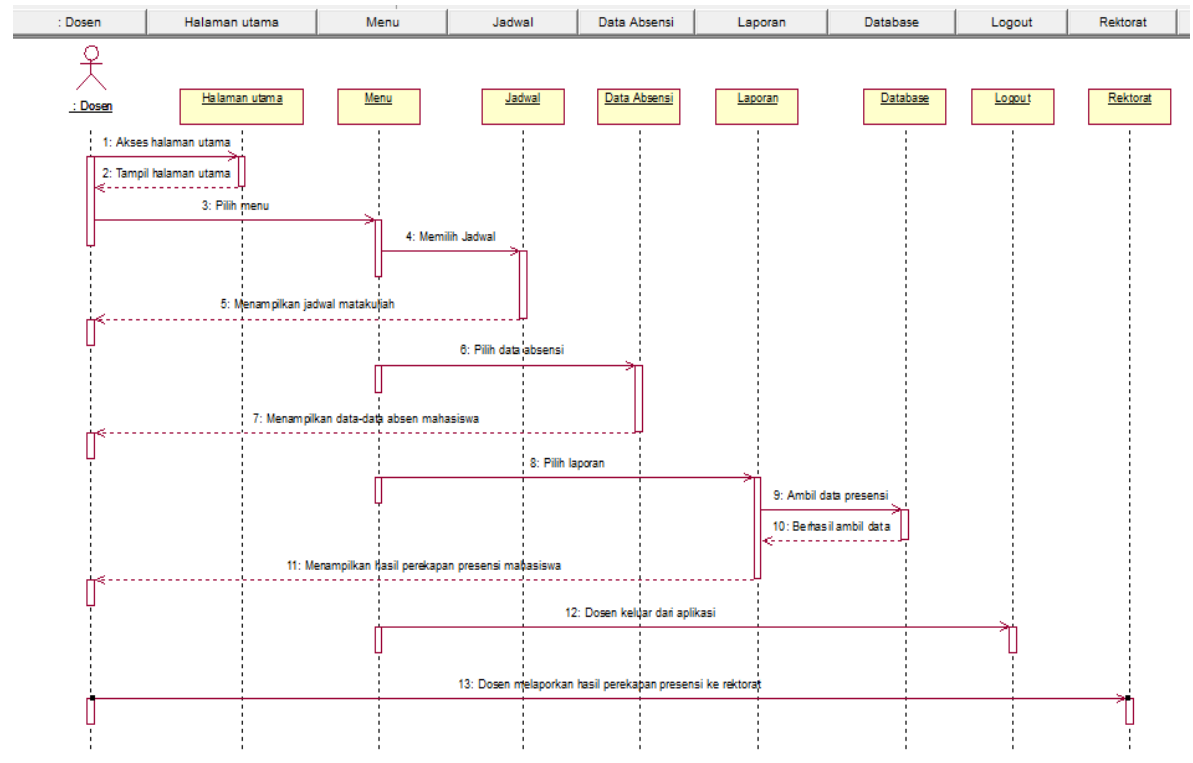

Gambar 7. Sequence Laporan

Tahap akhir sebelum pembuatan perangkat lunak adalah melakukan perbaikan atau Critical Design Review. Pada tahap ini kembali melakukan review untuk memastikan bahwa tidak ada yang kurang pada sequence diagram. Memastikan bahwa setiap class yang ada telah memiliki atribut dan operasi yang didefinisikan secara lengkap (memiliki nama, tipe data, parameter, dan sebagainya). Pada tahap ini sudah lengkap dan dapat dilanjutkan ke tahap pembuatan perangkat lunak.

Langkah berikutnya adalah pembuatan aplikasi berdasarkan desain yang telah dibuat sebelumnya. Halaman login untuk bisa masuk kedalam sistem presensi, pengguna mengisi username dan password. Bila username atau password salah, sistem akan menampilkan informasi bahwa username atau password salah. Tampilan halaman home seperti pada Gambar 8. Tampilan Beranda admin merupakan halaman awal pada saat pengguna melakukan login sebagai admin, didalam halaman ini terdapat menu yang berisi data dosen, data mahasiswa, data matakuliah, proses krs, proses absensi, laporan absensi dan logout. Tampilan seperti pada Gambar 9 


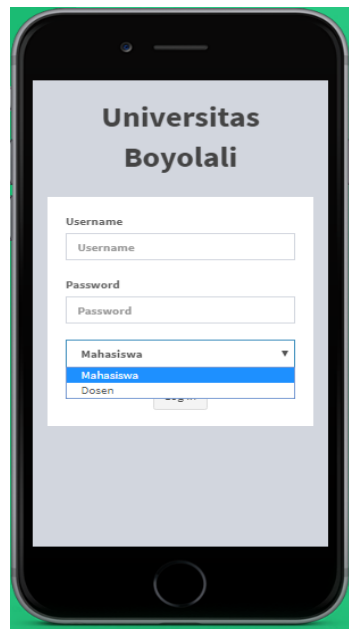

Gambar 8. Tampilan Home

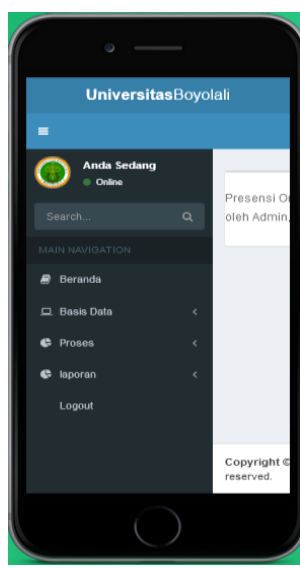

Gambar 9. Tampilan Admin

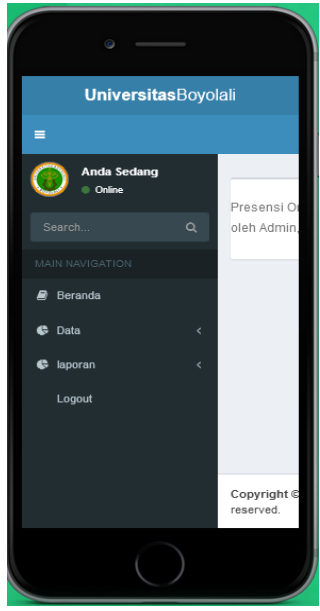

Gambar 10. Tampilan Dosen

Beranda dosen merupakan halaman awal pada saat pengguna melakukan login sebagai dosen, didalam halaman ini terdapat menu yang berisi data jadwal, data absensi dan logout. Tampilan seperti pada Gambar 10. Beranda mahasiswa merupakan halaman awal pada saat pengguna melakukan login sebagai mahasiswa, didalam halaman ini hanya terdapat data absensi untuk melakukan presensi dan logout. Tampilan seperti pada Gambar 11.

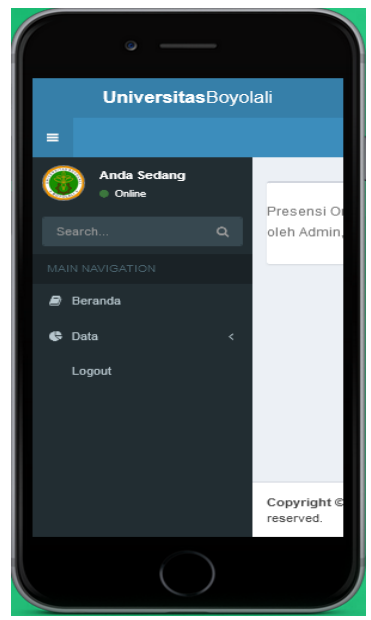

Gambar 11. Tampilan Beranda Mahasiswa

\section{Kesimpulan}

Berdasarkan pembahasan yang telah diuraikan maka dapat disimpulkan bahwa hasil penelitian ini telah berhasil merancang, mengimplementasikan, dan menguji aplikasi presensi online untuk proses pengajaran di Universitas Boyolali dan memudahkan dalam proses absensi dan perekapan absensi setiap semester. Kemudahan yang diberikan bagi mahasiswa dengan memanfaatkan androidnya dapat melakukan absensi pada saat mengikuti perkuliahan. Sedangkan bagi Dosen dapat langsung melihat dan mengetahui mahasiswa yang sudah melakukan absensi. Upaya pengembangan lebih lanjut disarankan untuk membuat pengelompokan matakuliah dari berbagai program studi di Universitas Boyolali dan perlunya pelatihan penggunaan aplikasi ini agar semua dosen dapat mengoperasikannya. 


\section{Ucapan Terima Kasih}

Terima kasih diberikan kepada Fakultas Ilmu Komputer Universitas Boyolali yang telah memberikan ijin untuk tempat penelitian.

\section{Daftar Pustaka}

[1] Hartaji, Damar A. 2012. Motivasi Berprestasi Pada Mahasiswa yang Berkuliah Dengan Jurusan Pilihan Orangtua. Fakultas Psikologi Universitas Gunadarma.

[2] Indri Neforawati, Muhammad Irdam Fareza, Vida Juniarti. 2015. Rancang Bangun Aplikasi Sistem Informasi Monitoring Absensi Mahasiswa Politeknik Negeri Jakarta Menggunakan Teknologi Nfc Pada Android. Vol 14. No. 2 (2015). Jurnal Poli Teknologi.Politeknik Negeri Jakarta Http://Jurnal.Pnj.Ac.Id/Index.Php/Politeknologi/Issue/View/58

[3] Mukhamad Taqwa Nuddin Dan Diana Laily Fithri (2015) Melakukan Penelitian Dengan Judul Sistem Absensi Asisten Dosen Menggunakan Qr Code Scanner Berbasis Android Pada Program Studi Sistem Informasi Universitas Muria Kudus. Prosiding Snatif. https://jurnal.umk.ac.id/index.php/SNA/article/view/338

[4] Fransiskus Adi Kara.2016. Pengembangan Fungsi Pengajuan Cuti Karyawan pada Sistem Absensi Mobile.Vol 6 No 1. Jurnal SISFO. Departemen Sistem Informasi. Institute Teknologi Surabaya. http://is.its.ac.id/pubs/oajis/index.php/home/detail/1637/Pengembangan-FungsiPengajuan-Cuti-Karyawan-pada-Sistem-Absensi-Mobile

[5] Wijayanto, Eko. 2017. Sistem Presensi Mahasiswa Dengan Fingerprint Berbasis Website. Surakarta: Universitas Muhammadiyah Surakarta.

[6] Husain, A., Prastian, A. H. A., \& Ramadhan, A. (2017). Perancangan Sistem Absensi Online Menggunakan Android Guna Mempercepat Proses Kehadiran Karyawan Pada PT. Sintech Berkah Abadi. Technomedia Journal, 2(1), 105-116. https://doi.org/https://doi.org/1 0.33050/tmj.v2i1.319

[7] Ristyawan Aidina, Dwi Harini. 2019. Proses Iconix Dalam Analisa Rancangan Aplikasi Informasi Jadwal Dan Tugas Berbasis Android. Jurnal SIMETRIS, Vol. 10 No. 1 April 2019. Fakultas Teknik. Universitas Muria Kudus. https://jurnal.umk.ac.id/ index.php/simet/ article/view/2685/1650 